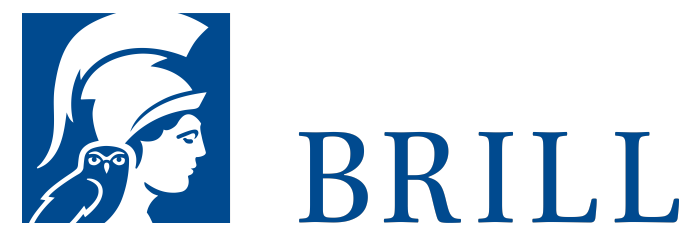

\title{
Gerechte Gewalt?
}

Zum Begriff interpersonaler Gewalt und ihrer moralischen Bewertung

Author: Daniel Meßelken

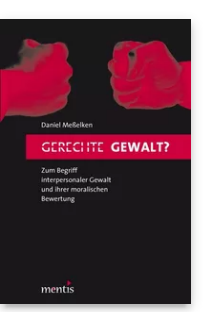

Kriege, Terrorismus, Völkermord, humanitäre Interventionen und andere Formen kollektiver Gewalt sind in den letzten Jahren auch in der Philosophie verstärkt in den Blickwinkel gerückt. Dabei wurde der Tradition des 'gerechten Krieges' neue Aufmerksamkeit zuteil und somit der Frage, ob und wann Kriege als 'moralisch gerechtfertigt' bewertet werden können. Die grundlegendere Frage, wie 'Gewalt' definiert werden kann, ist hingegen kaum nicht beachtet worden. Im Mittelpunkt des vorliegenden Buches steht die Frage nach Gründen für die moralische Rechtfertigung oder moralische Verurteilung gewaltsamen Handelns. Zur methodischen Vereinfachung wird nur so genannte interpersonale Gewalt, also der Einsatz von Gewalt durch genau eine Person gegen eine andere Person, betrachtet. Das Buch gliedert sich in drei Teile: Im ersten Teil wird die Idee vom 'gerechten Krieg' vorgestellt und gezeigt, das grundsätzlich auch heute noch an die klassischen Autoren angeknüpft werden kann. Der zweite Teil liefert einen Überblick über philosophische Positionen zum Begriff der Gewalt. Der dritte Teil führt die Ergebnisse zusammen und liefert (i) eine Explikation des Begriffs interpersonaler Gewalt und (ii) einen Rahmen zur Bewertung verschiedener Fälle derartiger Gewalt. Damit eine konkrete Gewaltanwendung als gerechtfertigt gelten kann, muss sie einer Liste von Kriterien genügen. Dieses Buch diskutiert...

Pages: 248

Seiten

Language:

German

Subjects:

General,

Philosophy

Publisher: Brill | mentis

E-Book (PDF)

Released online: 16 Jan 2012

ISBN: 978-3-

95743-968-о

List price

USD $\$ 52.00$

Paperback

Publication date: 16 Jan 2012

ISBN: $978-3^{-}$

89785-751-3

List price

USD $\$ 52.00$ 
For more information see brill.com

Order information: Order online at brill.com +44330 333 0049 | customerservices@brill.com Submission information: brill.com/authors

Titles published by Brill | Fink, Brill | mentis or Brill | Schöningh: +49(o)715413279216| brill@brocom.de 